\title{
Droplet Burning of JP-8/Silica Gels
}

\author{
R. Arnold*, W. E. Anderson ${ }^{\dagger}$ \\ Department of Aeronautical and Astronautical Engineering, Purdue University, \\ West Lafayette, IN 47907, USA
}

For future high performance rocket launchers, gelled propellants have the potential to replace conventional solid and liquid fuels by combining the individual advantages of both systems and neglecting the most disadvantages at the same time. Since gels show different atomization, spray and combustion behavior in comparison to liquid propellants, the investigation of single droplet vaporization and combustion is fundamental for the understanding of designing a gel operated injector system. Based on a rheological characterization of gelled JP-8 turbine fuel using fumed silica as a gelling agent, single droplet combustion experiments have been conducted. Combustion experiments have shown a typical $d^{2}$-law behavior with considerable influence of the gelling agent. A higher amount of gellant agent results in a reduced burning rate. Droplet size as well as droplet temperature during combustion depend strongly on the consistency of the gel.

\section{Nomenclature}

$B \quad$ Spalding number (-)

$c_{p} \quad$ specific heat capacity $(\mathrm{J} /(\mathrm{kgK}))$

$d \quad$ diameter $(\mathrm{m})$

$D$ diffusivity $\left(\mathrm{m}^{2} / \mathrm{s}\right)$

$f_{\text {st }} \quad$ stoichometric fuel/oxidizer ratio (-)

$k$ thermal conductivity $(\mathrm{W} /(\mathrm{mk}))$

$K \quad$ consistency index (-)

$K \quad$ burning rate constant $\left(\mathrm{m}^{2} / \mathrm{s}\right)$

$K^{\prime} \quad$ effective burning rate constant $\left(\mathrm{m}^{2} / \mathrm{s}\right)$

$\bar{K}^{\prime} \quad$ time-averaged eff. burning rate constant $\left(\mathrm{m}^{2} / \mathrm{s}\right)$

$L_{\mathrm{v}} \quad$ latent heat of vaporization $(\mathrm{J} / \mathrm{kg})$

$m$ mass $(\mathrm{kg})$

$\dot{m}$ mass flow rate $(\mathrm{kg} / \mathrm{s})$

$M \quad$ gelling agent mass fraction (-)

$n \quad$ power-law index $(-)$

$t$ time (s)

$T$ temperature $(\mathrm{K})$ $\dot{\gamma} \quad$ shear rate $(1 / \mathrm{s})$

$\eta \quad$ viscosity $(\mathrm{Pa} \cdot \mathrm{s})$

$\eta_{0} \quad$ yield viscosity $(\mathrm{Pa} \cdot \mathrm{s})$

$\eta_{\infty} \quad$ viscosity at high shear rates $(\mathrm{Pa} \cdot \mathrm{s})$

$\rho \quad$ density $\left(\mathrm{kg} / \mathrm{m}^{3}\right)$

Subscript

0 initial condition

$\infty$ ambient

b burning

cal calculation

d droplet

exp experiment

g gas

gel gelling agent

liq liquid

s surface

\section{Introduction}

DVAntages of gelled propellants are almost liquid-propellant like high performance, wide range thrust A control and re-ignitability in addition to solid-propellant like storage behavior and safety aspects. ${ }^{1}$ Furthermore, gels allow for the addition of metallic particles like aluminium, magnesium or boron during the gel mixing process to increase engery density of the propellant and thrust of the engine. During storage in the propellant tank, gels are solid-like with a very good leakage behavior in terms of spillage and with a

*Post Doctoral Scientist, AIAA Member, Email: arnold17@purdue.edu

${ }^{\dagger}$ Associate Professor, AIAA Senior Member, Email: wanderso@purdue.edu 
ruptured tank structure. However, when shear stress is applied to the gel, viscosity decreases and the gel can be pumped and injected into the combustion chamber like a typical liquid propellant. Storage stability is a very important factor for long duration applications and a further advantage of gels compared to some liquid propellants.

However, before gels can be widely used, their atomization and burning processes must be wellunderstood. In addition, a gel propellant feed system will require detailed information about fluid properties and pressure loss characteristics due to higher viscosities and therewith connected higher loads for the propellant feed system compared with typical liquid rocket engines. For these reasons, gels envisaged for the application in a future rocket propulsion system have to show a shear-thinning behavior. ${ }^{2}$

Since the typical requirements for gelled and liquid propellants are similar in terms of chemical stability during storage, thermal stability during the combustion process and high overall system performance, investigations in the past concentrated mainly on fuels like MMH (Monomethylhydrazine) and UDMH (Unsymmetrical dimethylhydrazine), DMAZ (2-Dimethylaminoethylazide), and also different types of hydrocarbon jet propellants like JP-5, JP-8, JP-10 and rocket propellant RP-1. Typical oxidizers are WFNA (White fuming nitric acid), IRFNA (Inhibited red fuming nitric acid) and NTO (Nitrogen tetroxide). ${ }^{3}$ To create a gel, inorganic gelling agents which stay unburned during combustion, and organic gelling agents which are burned together with the propellant can be distinguished. The most common inorganic gelling agent is fumed silica $\left(\mathrm{SiO}_{2}\right)$, which is typically used to produce gelled nitric acid. Typical organic gelling agents are cellulose based derivatives like HPC (Hydroxypropylcellulose), HEC (Hydroxyethylcellulose) and HAC (Hydroxyalkylcellulose). ${ }^{3,4}$ The most promising combinations of gelled propellants for rocket applications are deduced from approved liquid hypergol combinations, but also a specific amount of metallic additives may be added to the oxidizer/fuel combination to increase the performance, for example $\mathrm{MMH} / \mathrm{Al} / \mathrm{IRFNA}$ and $\mathrm{MMH} / \mathrm{Al} / \mathrm{NTO}$. Gelled metallized hydrocarbons like Al/RP-1 with an acrylic acid polymer resin and laurylamine as gelling agent have been investigated in terms of a high density storable propellant for booster applications and have also been considered for single-stage-to-orbit (SSTO) studies. ${ }^{5}$ The first successful flight of a missile system in 1999 using a carbon loaded MMH fuel gel and an IRFNA oxidizer gel demonstrated the technical readiness of gelled propellant technology. ${ }^{6}$

\section{A. Propellant description}

Untreated fumed silica $\mathrm{SiO}_{2}$ (CAB-O-SIL $\AA$ grade $\mathrm{M}-5$ ) has been used to produce gelled hydrocarbon propellants for the present investigations. In general, silica results from a combustion process of silicon tetrachloride $\left(\mathrm{SiCl}_{4}\right)$ in a $\mathrm{H}_{2} / \mathrm{O}_{2}$ flame. ${ }^{8}$ Due to agglomeration a white, non-porous fluffy powder is created with an agglomeration size of less than $44 \cdot 10^{-6} \mathrm{~m}$ and a hydrogen chloride level of less than $60 \mathrm{ppm}$ after a following calcining process. The aggregate chains of the silica are hereby a composition of fused together single particles. Table 1 gives an overwiew of typical properties of CAB-O-SIL $\AA$ M- $5 .{ }^{7}$

The surface of the silica has hydrophilic characteristics and is capable of building up hydrogen bonds to create a gel when mixed with the pure liquid due to chemical groups - isolated hydroxyl groups (hydrophilic), hydrogen-bonded hydroxyl groups (hydrophilic) and siloxane groups - which are attached to the surface of the silica during the formation process. Due to the hydrogen bonds between single silica aggregates in a dispersed liquid system, increased viscosity and thixotropic behavior is the result. The application of a shear force destroys the hydrogen bonds between the aggregates and results in a reduced viscosity (see figure 1 ).

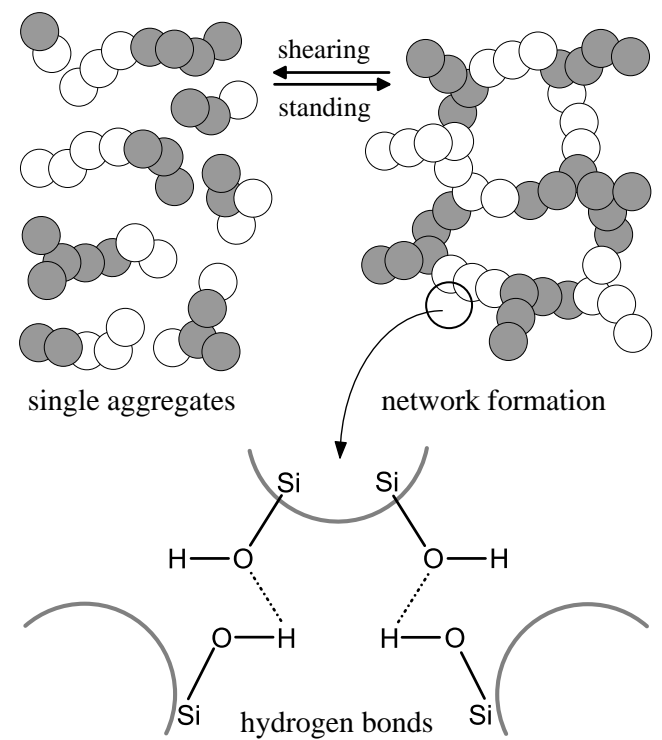

Figure 1. Silica aggregates, hydrogen bonds, and network formation (according to ${ }^{7}$ )

JP-8 (jet propellant; NATO code F-34) is the U.S. Air Force primary jet fuel, replacing JP-4 in 1995 because of its less flammable character, better safety and higher combat survivability. The average propellant composition comprises aromatics (18 vol\%), naphthenes (20 vol\%), paraffins (60 vol\%), olefins (2 vol\%) and 
sulfur with $490 \mathrm{ppm} .{ }^{9}$ Typical properties of the investigated hydrocarbon fuel JP-8 are summarized in Table $2 .^{9-11}$

Table 1. Properties of CAB-O-SIL\& M-5

\begin{tabular}{lr}
\hline \hline B.E.T. surface area $\left(\mathrm{m}^{2} / \mathrm{g}\right)$ & 200 \\
tamped density $(\mathrm{g} / \mathrm{l})$ & 50 \\
specific gravity $\left(\mathrm{g} / \mathrm{cm}^{3}\right)$ & 2.2 \\
average particle length $\left(10^{-6} \mathrm{~m}\right)$ & $0.2 \ldots 0.3$ \\
assay $\left(\% \mathrm{SiO}_{2}\right)$ & $>99.8$ \\
melting point $(\mathrm{K})$ & $\approx 1983$ \\
\hline \hline
\end{tabular}

Table 2. JP-8 properties

\begin{tabular}{lr}
\hline \hline approx. formula & $\mathrm{C}_{11} \mathrm{H}_{21}$ \\
gravity at $293 \mathrm{~K}\left(\mathrm{~g} / \mathrm{cm}^{3}\right)$ & $0.76 \ldots 0.84$ \\
flash point $(\mathrm{K})$ & $\mathrm{min} .310$ \\
boiling range $(\mathrm{K})$ & $430 \ldots 573$ \\
critical temperature $(\mathrm{K})$ & 683 \\
critical pressure $(\mathrm{MPa})$ & 2.34 \\
\hline \hline
\end{tabular}

\section{B. Gel preparation}

For the preparation of the JP-8 gels an acoustic high-shear mixing technique (Resodyn ResonantAcoustic@ LabRAM) has been used. The applied acoustic mixing process uses low-frequency, high-intensity acoustic energy, resulting in a uniform shear level inside the mixing container. During mixing, the entire system oscillates in resonance frequency, which gives a very high dispersion in the mixing container and produces very high shear rates. ${ }^{12}$ Micro-scale turbulences are created inside the medium by the acoustic waves, resulting in a very consistant mixing of the liquid and the gelling agent by applying accelerations up to $100 \mathrm{~g}$.

To characterize the silica concentration of the gels, the mass fraction $M$ describes the gelling agent amount $m_{\text {gel }}$ in comparison to the total propellant mass, given by the mixture of liquid $m_{\text {liq }}$ and gelling agent $m_{\text {gel }}$ :

$$
M=\frac{m_{\text {gel }}}{m_{\text {liq }}+m_{\text {gel }}}
$$

\section{Rheological characterization}

A gel consists at least the original propellant and the added gelling agent. The amount of gelling agent as well as the liquid/gelling agent combination controls the rheological characteristics of the gel. Gels are non-Newtonian fluids which have an almost solid-like behavior when no shear stress is applied. In general, for a Newtonian liquid the dynamic viscosity $\eta$ can be expressed as a function of shear stress $\sigma$ and shear rate $\dot{\gamma}$ :

$$
\eta=\frac{\sigma}{\dot{\gamma}}
$$

For a non-Newtonian liquid the viscosity $\eta$ is dependent on the applied shear rate $\dot{\gamma}$. For the characterization of Newtonian and non-Newtonian fluids without a yield point, the power-law model (Ostwald-de Waele model) is the most common correlation: ${ }^{13}$

$$
\eta=K \dot{\gamma}^{n-1}
$$

where $K$ is the consistency index, and $n$ is the power-law index of the fluid. For $n=1$ equation (3) describes a Newtonian fluid. However, shear thinning behavior appears a power-law index $0<n<1$, and shear thickening (dilatant behavior) for $n>1$.

The Herschel-Bulkley model (HB) is a simple description for non-linear gels which also considers a yield stress $\sigma_{0}$ for low and medium shear rates: ${ }^{13}$

$$
\eta=\eta_{0}+K \dot{\gamma}^{n-1}
$$

Finally, an extended version of the Herschel-Bulkley equation (HBE) takes into account the minimum viscosity $\eta_{\infty}$ at very high shear rates: ${ }^{13,14}$

$$
\eta=\eta_{0}+K \dot{\gamma}^{n-1}+\eta_{\infty}
$$

With the HBE viscosities at typical rocket engine and ramjet injection conditions with shear rates above $10^{5} \mathrm{~s}^{-1}$ can be considered, whereas the HB model would under-predict viscosities at these conditions with values far below the viscosity of the pure liquid. ${ }^{15}$ However, it is important to emphasize that neither of these models consider time-dependent effects. 


\section{A. Measuring system}

For the rheological characterization of the gelled fuels a rotational rheometer operated in controlled rate mode (CRR) has been used. The rotational rheometer imposes strain to the liquid and measures the resulting stress for shear rates up to $1000 \mathrm{~s}^{-1}$. A cone-and-plate configuration has been used for the present investigations because it allows homogeneous strain in the gelled liquid. For the measurements of the pure liquid however, a concentric cylinder has been used because of the low viscosity. A temperature control system inside the equipment made sure to obtain a constant fluid temperature of $298 \mathrm{~K}$ during all rheological measurements.

\section{B. Viscosity and thixotropic behavior}

The viscosity of the gels and of the pure liquid for shear rates of $1 \ldots 1000 \mathrm{~s}^{-1}$ is depicted in figure 2. A significant increase of the viscosity as a function of the added silica amount $M$ is clearly visible especially for shear rates up to $250 \mathrm{~s}^{-1}$, whereas for higher shear rates and silica amounts of $5 \ldots 7 \%$ almost identically results have been measured. Figure 2 demonstrates also the differences between the almost Newtonian-like pure ungelled JP-8, where the viscosity is not dependend on the applied shear rate, and the non-Newtonian gels using fumed silica as a gelling agent. ${ }^{16}$

Shear-thinning non-Newtonian fluids show a decreasing viscosity when an increasing shear rate is applied. Thixotropic fluids also show a decreasing viscosity over time when a constant shear rate is maintained. Due to the application of shear to the silica gels the interaggregate hydrogen bonds

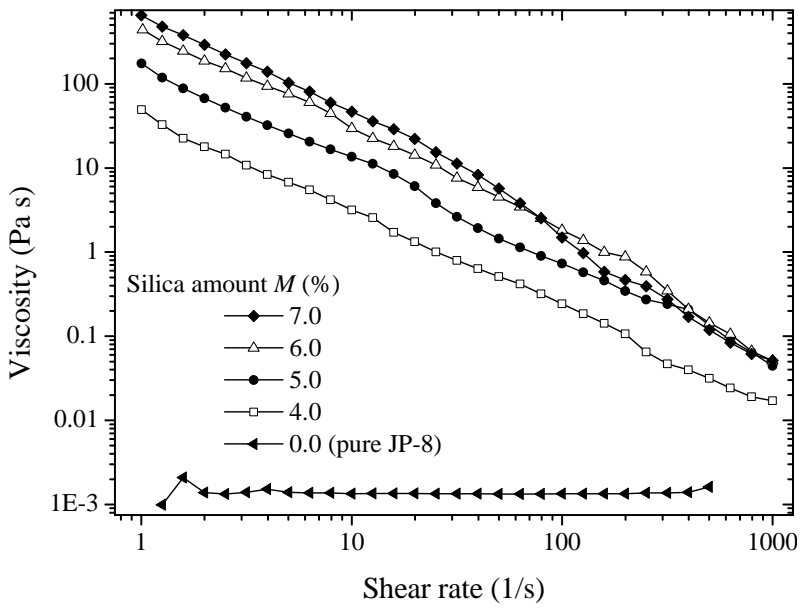

Figure 2. Viscosity as a function of silica amount break, which leads to a decrease of the apparent gel viscosity. It has been reported, that once the shear force has been removed, the bonds rebuild over time and the viscosity approaches its original value. ${ }^{7}$ This behavior could be restrictive for the application in a gelled propellant engine, since the redevelopment of the hydrogen bonds would increase viscosity and pressure loss of the entire system. Once pumped from the storage tank, gelled propellants should show a low viscosity to unburden the pump system, and good vaporization and combustion behavior. Figure 3 depicts the application of a shear rate $\dot{\gamma}=100 \mathrm{~s}^{-1}$ for $180 \mathrm{~s}$ to destroy the hydrogen bond system and to break the gel. After a time interval of $\Delta t=480 \mathrm{~s}$ with no

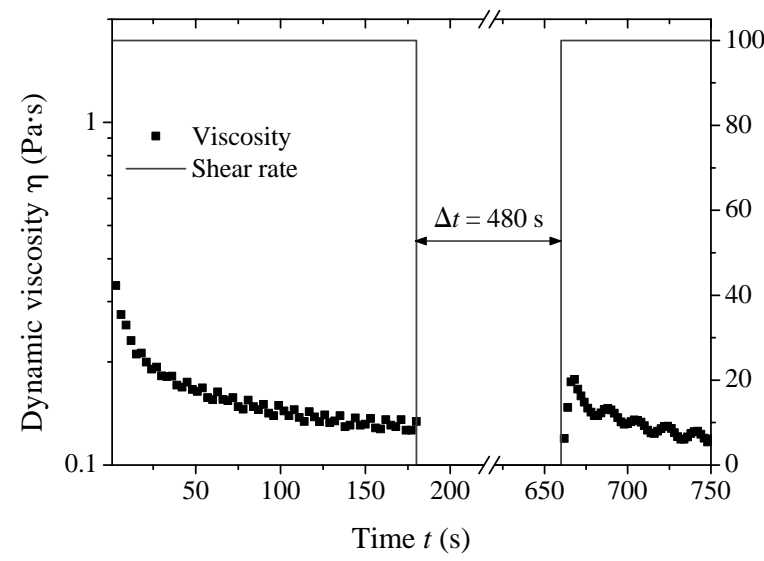

(a) JP- $8, M=4 \%$

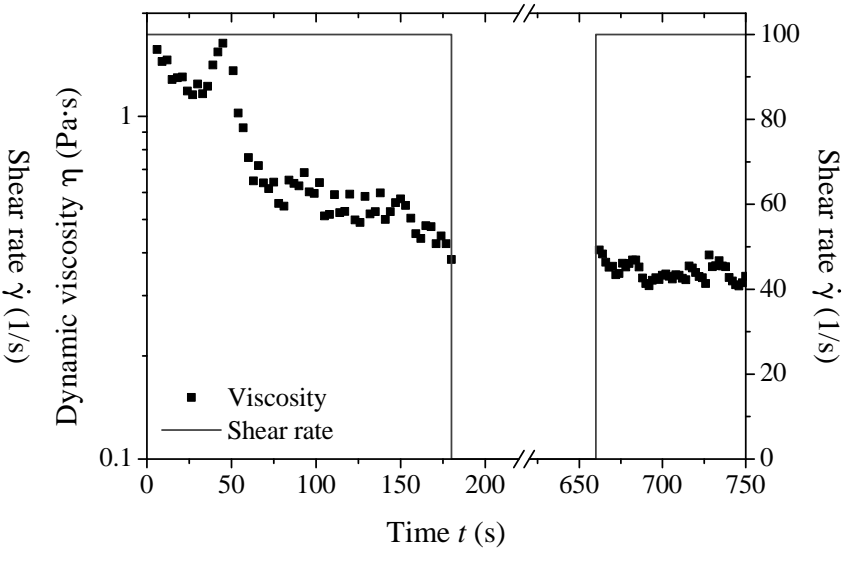

(b) JP- $8, M=7 \%$

Figure 3. Thixotropic behavior of JP-8/silica gels

shearing, the original shear rate is applied again. It is clearly visible that there is no gel recovery after this time. The gel viscosity after the break is comparable to the viscosity when the shearing is stopped. This 
behavior is independent from the gelling agent amount. Since the gel structure is destroyed mostly after the first shearing period, the viscosity is only slightly reduced in the second shearing period.

\section{Droplet combustion}

Since the combustion characteristics of gelled propellants are still not fully understood, a number of investigations have been performed in the past. The Israel Institute of Technology (Technion) has shown results from droplets of water gels ${ }^{17}$ and hydrocarbon based gels (kerosene, ${ }^{18} \mathrm{JP}-5,{ }^{19,20} \mathrm{JP}-8^{21,22}$ ), indicating that the amount of the added gelling agent has a strong influence on the burning behavior of the droplets in comparison to the ungelled pure liquid.

In general, the mass balance for a droplet featuring the mass $m_{\mathrm{d}}(t)$ during combustion is given by:

$$
\frac{\mathrm{d} m_{\mathrm{d}}}{\mathrm{d} t}=-\dot{m}
$$

With consideration of the droplet-gas-phase interface energy balance and the assumption of a quasi-steady evaporation and burning, a Lewis number of unity and a uniform droplet temperature $T_{\mathrm{d}}$ equal to the boiling temperature of the fluid $T_{\text {boil }}$ it can be written: ${ }^{23}$

$$
\frac{\mathrm{d} d_{\mathrm{d}}^{2}}{\mathrm{~d} t}=-\frac{8 k_{\mathrm{g}}}{\rho_{\mathrm{d}} c_{p, \mathrm{~g}}} \ln (B+1)
$$

$\rho_{\mathrm{d}}$ and $\rho_{\mathrm{g}}$ are the densities of the droplet and the gas, respectively, $k_{\mathrm{g}}$ the thermal conductivity of the gas, $c_{p, \mathrm{~g}}$ the specific heat of the gas, and $B$ is the Spalding transfer number, which represents the enthalpy ratio exiting the gas and entering the droplet during phase transformation processes:

$$
B=\frac{c_{p, \mathrm{~g}}\left(T_{\infty}-T_{\mathrm{s}}\right)+H_{\mathrm{R}} f_{\mathrm{st}} m_{0, \infty}}{L_{\mathrm{v}}}
$$

$T_{\infty}$ and $T_{\mathrm{s}}$ describe the ambient temperature and the droplet surface temperature, respectively, whereas $H_{\mathrm{R}}$ is the heat of reaction, $f_{\text {st }}$ the stoichometric ratio between fuel and oxidizer, $m_{0, \infty}$ the ambient oxygen mass fraction, and $L_{\mathrm{v}}$ the latent vaporization heat of the investigated fuel.

The addition of a gelling agent will change the Spalding number which controlls the reaction by changing the heat of vaporization of the droplet. To take into account the influence of the gelling agent on the heating up of the droplet, the effective heat of vaporization can be used for the period when the surface temperature and the droplet temperature, $T_{\mathrm{s}}$ and $T_{\mathrm{d}}$ respectively, are not in agreement: ${ }^{2}$

$$
L_{\mathrm{v}, \text { eff }}=L_{\mathrm{v}}+c_{p, \mathrm{~d}}\left(T_{\mathrm{s}}-T_{\mathrm{d}}\right)
$$

In general, diffusion controlled droplet burning can be characterized by a typical $d^{2}$-law, which describes the relation between the total droplet burning time $t_{\mathrm{b}}$ and the initial droplet square diameter $d_{0}^{2}$ before ignition takes place. As it can be seen in equation (7), the present square droplet diameter $d_{\mathrm{d}}^{2}(t)$ is a linear function of the time $t$ with a slope $K$, which is defined as the burning rate constant (see figure 4 ):

$$
K=\frac{8 k_{\mathrm{g}}}{\rho_{\mathrm{d}} c_{p, \mathrm{~g}}} \ln (B+1)
$$

It should be noted that $K$ is only a constant when a steady-state droplet surface temperature is reached. Due to the small mass of the investigated droplets and the high heating rates in this experiment, this assumption is reasonable. By the use of the correlation:

$$
\frac{k_{\mathrm{g}}}{c_{p, \mathrm{~g}}}=\rho_{\mathrm{g}} D
$$

where $D$ describes the diffusivity of oxygen, equation (10) can also be written:

$$
K=\frac{8 D \rho_{\mathrm{g}}}{\rho_{\mathrm{d}}} \ln (1+B)
$$


The simplified $d^{2}$-law for droplet evaporization and combustion can be stated as: ${ }^{23}$

$$
d_{\mathrm{d}}^{2}(t)=d_{0}^{2}-K t
$$

Finally, the total droplet burning time or droplet lifetime $t_{\mathrm{b}}$, defined as the span of time between the first detection of the flame and the flame extinction, which is given for $d_{\mathrm{d}}^{2}\left(t_{\mathrm{b}}\right)=0$ can be evaluated from: ${ }^{23}$

$$
t_{\mathrm{b}}=\frac{d_{0}^{2}}{K}=\frac{\rho_{\mathrm{d}} d_{0}^{2}}{8 D \rho_{\mathrm{g}} \ln (1+B)}
$$

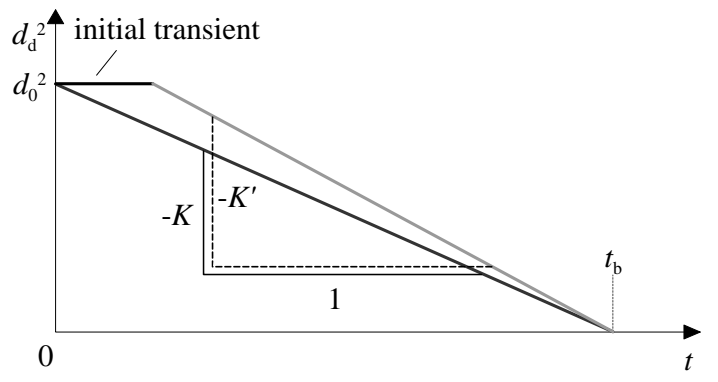

Figure 4. $d^{2}$-law for droplet burning (according to ${ }^{23}$ )

It should be noted that the burning rate equations (13) and (14) negelect the heating of the droplet and assume a $d^{2}$-law for the whole burning time. To consider this effect, a burning constant $K$ which is given by an averaged slope will be used to describe the burning behavior as a function of the overall droplet burning time $t_{\mathrm{b}}$ (see figure 4 ). On the other hand, an effective burning constant $K^{\prime}$ considers the initial transient which includes not only the droplet heating but also the disturbance due to the thermocouple on which the droplet is suspended during the burning, and is given by the local slope as depicted also in figure 4 . Especially for small droplets with a short burning time and a relatively small mass in comparison to the thermocouple inside the droplet, the differences between $K$ and $K^{\prime}$ are quite significant, and should also be considered when comparing measured and simulated burning rate constants.

Previous investigations have confirmed the $d^{2}$-law not only for pure hydrocarbon droplets, but also for gelled JP-5, using an organic metallic gellant. ${ }^{19,20}$ However, since the gelling agents may increase the latent heat of vaporization and also slightly the propellant density in comparison to the pure ungelled liquid, an increasing amount of gelling agent increases the droplet burning time. Besides a decreased burning rate with increased gelling agent amount, also a higher droplet burning temperature has been measured for increased gelling agent amounts. ${ }^{20}$

\section{A. Experimental setup}

For the single droplet investigations, static conditions have been chosen. A surrounding environment providing ambient pressure and temperature has been applied to protect the experiment from disturbing influences. A rectangular plexiglass housing provides perfect optical access without any distortion. For the droplet burning experiments, droplets of pure or gelled fuel have been suspended by a thin, horizontal arranged thermocouple wire (see figure 5), which was also adjustable in height to meet proper vertical positioning.

The optical measurement system consisted of a digital $30 \mathrm{fps}$ high resolution color video camera with a $100 \mathrm{~mm} \mathrm{f} / 2.8$ macro lens, and a digital black-andwhite high speed camera recording with a frame rate of $1000 \mathrm{fps}$ and an attached $105 \mathrm{~mm} \mathrm{f} / 2.8$ macro lens. An additional light source has been installed to backlight the droplets during vaporization and combustion to provide high image quality.

Ignition of the droplets has been done by the use of a small propane flame for its simplicity and controllability. The point of ignition has been detected by analyzing single frames of the captured video streams.

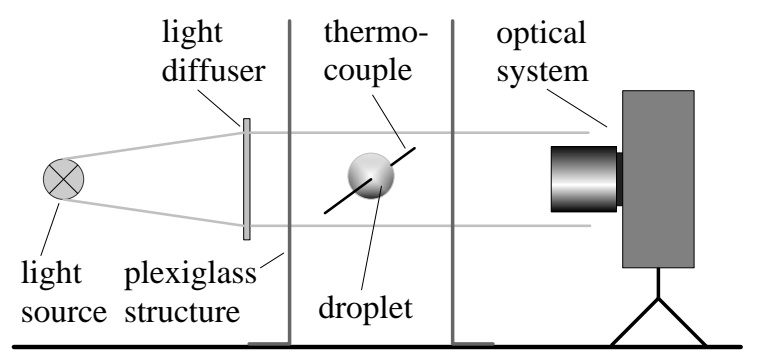

Figure 5. Experimental setup Since the burning time of the gelled droplets have been mostly in the range of several seconds, the accuracy of this method emerged adequately for the present study with a maximum burning time deviation far below $1 \%$ even when using the $30 \mathrm{fps}$ video camera for most of the investigated droplets. The high speed camera equipment can also detect the ignition point and total droplet burning time with high accuracy. However, 
due to the much higher optical quality of the 30 fps color video camera shots, the droplet size during combustion and resultant burning rate behavior could be described with a higher accuracy using the high resolution camera than by analyzing the monochrome $1000 \mathrm{fps}$ high speed videos.

To minimize the disturbance of the burning behavior due to the thermocouple, a variety of different thermocouple wire diameters in the range of $0.120 \ldots 0.013 \mathrm{~mm}$ was investigated. Due to the nonexistent surface tension of the gels when acting like a solid, low viscosity propellants with a low silica amount can only generate a small droplet diameter in comparison to liquids with higher amounts of silica and therefore higher initial viscosity (see figure 2). When choosing a thermocouple with a very thin wire diameter for a larger droplet with higher viscosity, the thermocouple is not able to hold the droplet in a stable position during combustion.

\section{B. Droplet burning behavior}

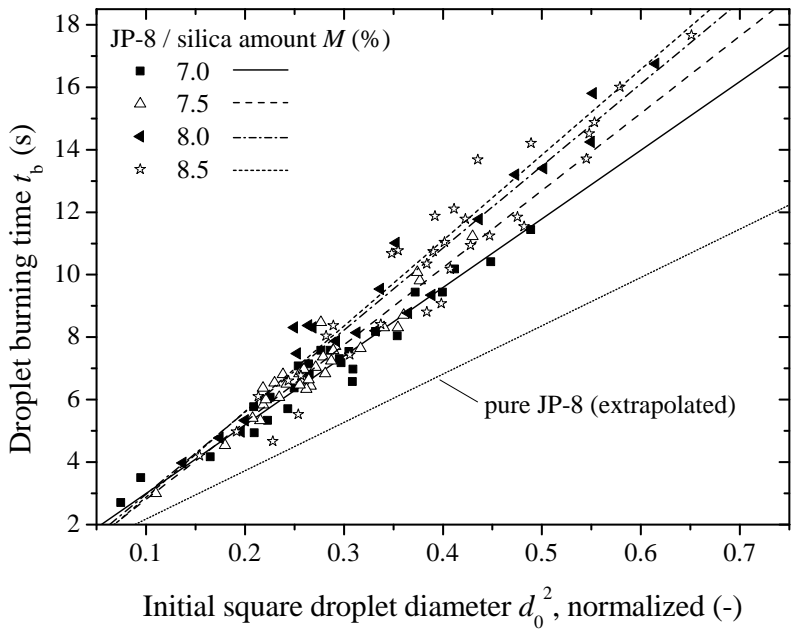

Figure 6. Burning time vs. initial diameter
Figure 6 shows the burning behaviour for gels with a high amount $M$ of silica, using $7 \%, 7.5 \%, 8 \%$ and $8.5 \%$ gelling agent. The linear correlation between the square droplet diameters and the burning time, $d_{0}^{2}$ and $t_{\mathrm{b}}$, respectively, is clearly visible for the gels. Further, an increased amount of silica increases the total burning time of the droplets slightly. For comparison, also the burning behavior for pure JP-8 is depicted in figure 6 . As mentioned above, previous publications using hydrocarbon fuels with organic gelling agents have shown comparable behavior. ${ }^{19,20}$

The squared droplet size $d_{\mathrm{d}}^{2}$ of single droplets as a function of the burning time $t$ is depicted in figure 7 (a) for pure JP-8 and in figure 7 (b) for gelled JP-8. For the pure JP-8 droplets a very good agreement with a typical $d^{2}$-law can be stated after an initial transient which demands about $30 \%$ of the total droplet burning time (see figure 7 (a)). Due to the heating of the thermocouple tip and the propel-

lant mass during that time, the overall burning constant $K$ and the effective burning constant $K^{\prime}$ (see figure 4) which considers the initial transient process diverge strongly.

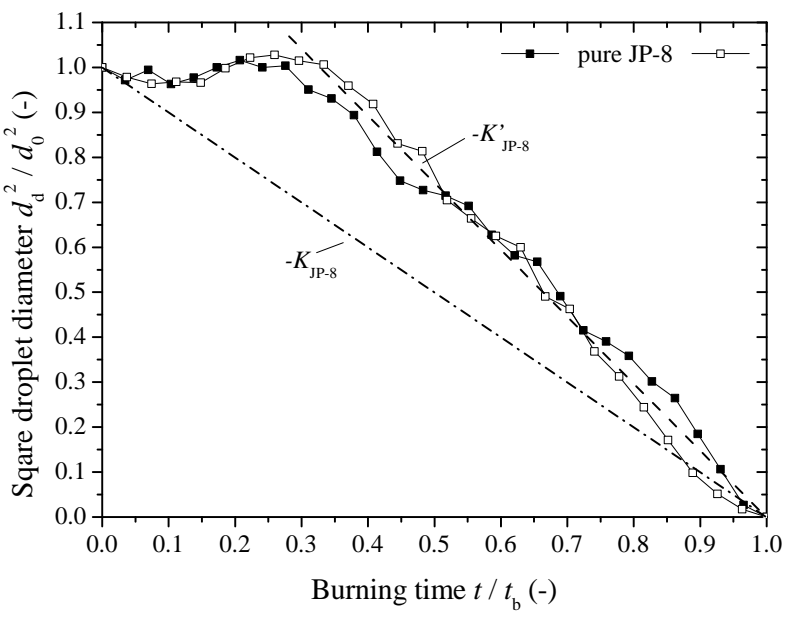

(a) Pure JP-8

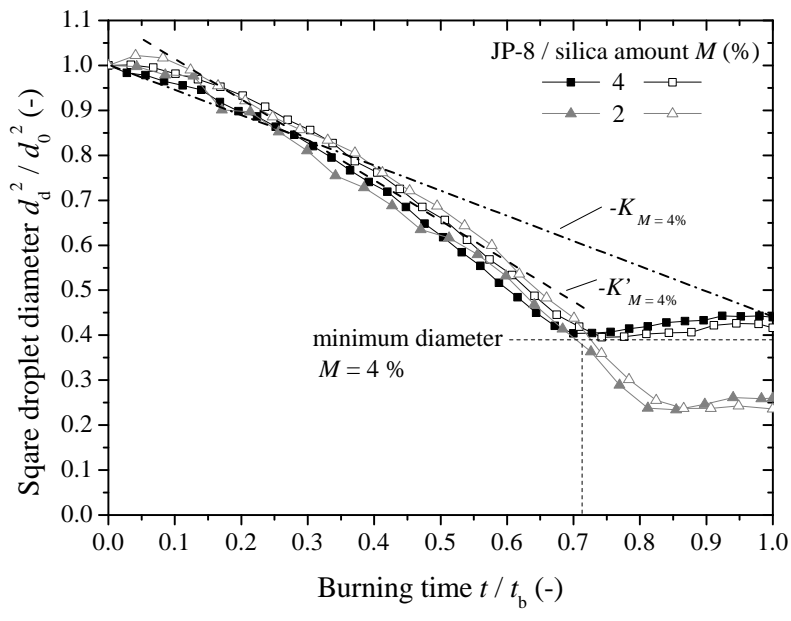

(b) Gelled JP-8

Figure 7. Droplet size during combustion

For the gelled JP-8 droplets the initial transient is much shorter (about $10 \%$ of the burning time), as shown in figure 7 (b). However, since the gelling agent stays unburned, the final droplet size after the 
extinction of the flame is $d_{\mathrm{d}}\left(t_{\mathrm{b}}\right)>0$. During the droplet burning, the silica particles cluster together and build a hollow, rigid structure with a final size that is a function of the gelling agent amount in the original droplet. After all the liquid surrounding the inner silica structure is burned, a minimum diameter is reached. The residual entrapped liquid is burned, which causes a slight swelling of the silica cluster. The time of the minimum drop diameter during combustion is also a function of $M$ and is reached approximetely after $70 \%$ of the burning time for the $4 \%$ gel and after approximately $80 \%$ for the $2 \%$ gel, respectively. For the interval after the initial transient up to the time of the minimum diameter, the typical $d^{2}$-law with the effective burning constant $K^{\prime}$ can be applied for the description of the burning behaviour. Due to the generation of the rigid silica structure at the end of the droplet burning, the overall burning constant $K$ (plotted for the $4 \%$ gel in figure 7 (b)) and the effective burning constant $K^{\prime}$ differ also for the gelled liquid. Surprisingly, the effective burning rates $K^{\prime}$ of the $2 \%$ and $4 \%$ gels are almost identical without a significant influence of the gelling amount $M$.

Figures 7 (a) and (b) illustrate that the typical $d^{2}$-law can be used for the description of the pure hydrocarbon fuel as well as for the gelled droplets. This is in agreement with previous investigations using organic metallic gells. ${ }^{19,20}$ Furthermore, investigations with a metallized organic JP-8 gel have shown that the remaining metal structure is actually about $1.5 \ldots 2$ times larger than the initial droplet size. ${ }^{21}$

A closer examination of the burning rate vs. burning time of the $4 \%, 2 \%$ and $0 \%$ gels is depicted in figure 8 (a). As mentioned above, the behavior of the pure ungelled liquid can be described in very good agreement with the typical $d^{2}$-law after an initial transient of approx. $35 \%$ of the total droplet burning time. For the gelled liquids however, an almost linear increase of the burning velocity can be seen with an abrupt decrease at the time when the minimum droplet diameter is reached (see figure 7 (b)). Although figure 7 (b) indicates the approach of the burning behavior of the gelled liquid to the $d^{2}$-law, the addition of comparatively small amounts $M$ of inorganic gelling agent changes the burning behavior quite significantly, as can be seen in figure 8 (a).

The comparison between the measured overall burning rate and a calculated burning rate following equation (10) is also depicted in figure 8 (a). Due to a lack of availability of JP-8 properties, 1-Undecene $\left(\mathrm{C}_{11} \mathrm{H}_{22}\right)$ has been used to simulate the hydrocarbon droplet behavior during combustion. The overall integral burning constant $K$ is smaller than the effective burning constant $K^{\prime}$ (see figures 4 and 7 ) due to the neglect of the initial transient and the remaining silica structure at the end of the burning process. However, the experimental and calculated burning rate constants $K$ show a very good agreement with $K_{\text {cal }} \approx 0.87 \mathrm{~mm}^{2} / \mathrm{s}$ (calculation) and $K_{\exp } \approx 1.06 \mathrm{~mm}^{2} / \mathrm{s}$ (experiment) for the ungelled liquid. The higher burning rate in the experiment in comparison to the calculated burning rate is notable since the thermocouple tip acts like a heat sink and slows down the heating of the droplet and therefore also the burning velocity, expressed by $K$.

To describe the influence of the gelling agent amount $M$ on the burning rate behaviour, a time averaged effective burning constant $\bar{K}^{\prime}$ has been used. The time intervall $t_{1} \ldots t_{2}$ taken into account for the calculation of $\bar{K}^{\prime}$ neglects initial transients at the beginning of the droplet burning and also the time period at the end with a solid silica structure for the gelled propellants (see figure 7):

$$
\bar{K}^{\prime}=\frac{1}{t_{2}-t_{1}} \int_{t_{1}}^{t_{2}} K^{\prime}(t) d t
$$

As depicted in figure $8(\mathrm{~b})$, the burning rate behavior as a function of the gelling agent amount $M$ can be described with an empirical function $f=f(M)$. The time averaged effective burning rate $\bar{K}^{\prime}(M)$ for gelled JP-8 can be written as a function of the time averaged effective burning rate $\bar{K}_{M=0}^{\prime}$ of the pure ungelled liquid and the amount of gelling agent $M$ in the gel:

$$
\bar{K}^{\prime}(M)=\bar{K}_{M=0}^{\prime} \frac{1}{1+0.2 \sqrt{M}}
$$

For a wide range of different gelling agent amounts $M=1 \ldots 8 \%$, equation (16) specifies the influence of the gelling agent on the burning rate with a very good agreement as shown in figure $8(\mathrm{~b})$.

Figure 9 depicts the buring process for gelled droplets and pure JP-8, divided into several sections, as a function of squared droplet diameter $d_{\mathrm{d}}^{2}$ and burning rate $K$. Section A describes the initial transient and is more pronounced for ungelled droplets. For pure liquid, section B is dominated by the burning process, which is characterized by the burning constant $K$. Constant burning speed and droplet temperature indicate the agreement with the typical $d^{2}$-law behavior. At the end of section $\mathrm{B}$, all fuel is burned and the flame is

$$
8 \text { of } 12
$$

American Institute of Aeronautics and Astronautics 


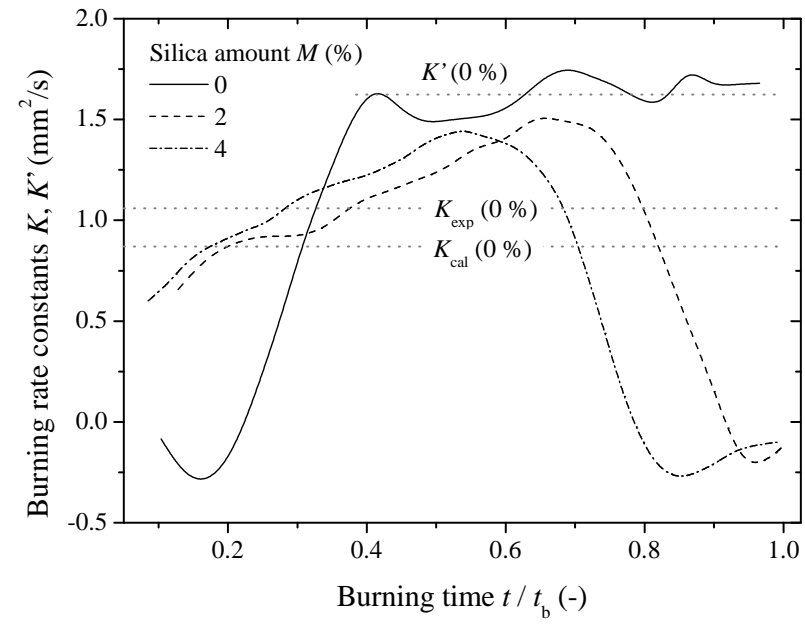

(a) Burning rate constant

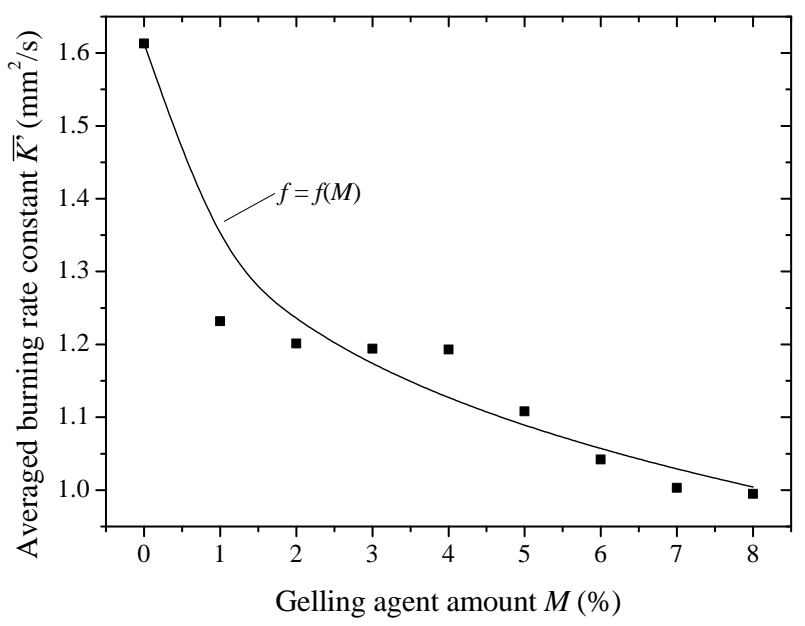

(b) Burning rate constant as a function of silica amount

Figure 8. Droplet burning rate

extinguished. For gelled droplets, section B describes the burning with a subsequentely increasing of burning velocity and droplet temperature. A description of the burning behavior with a $d^{2}$-law can only be done with restrictions in terms of an averaged burning constant. The silica shell is formed in this section, first cracks appear on the surface of the rigid structure. Section B ends with the minimum diameter, when the burning constant becomes 0 . For gelled droplets, a further section $\mathrm{C}$ exists. Here, residual fuel burns inside the rigid silica shell. More cracks can be detected in combination with irregular fuel vapor eruptions. The burning of the entrapped liquid causes a swelling of the silica structure during the last third of the burning time. As soon as all entrapped liquid is burned, the flame is extinguished at $t / t_{\mathrm{b}}=1$, remaining an unburned silica structure.

\section{Gelled JP-8}

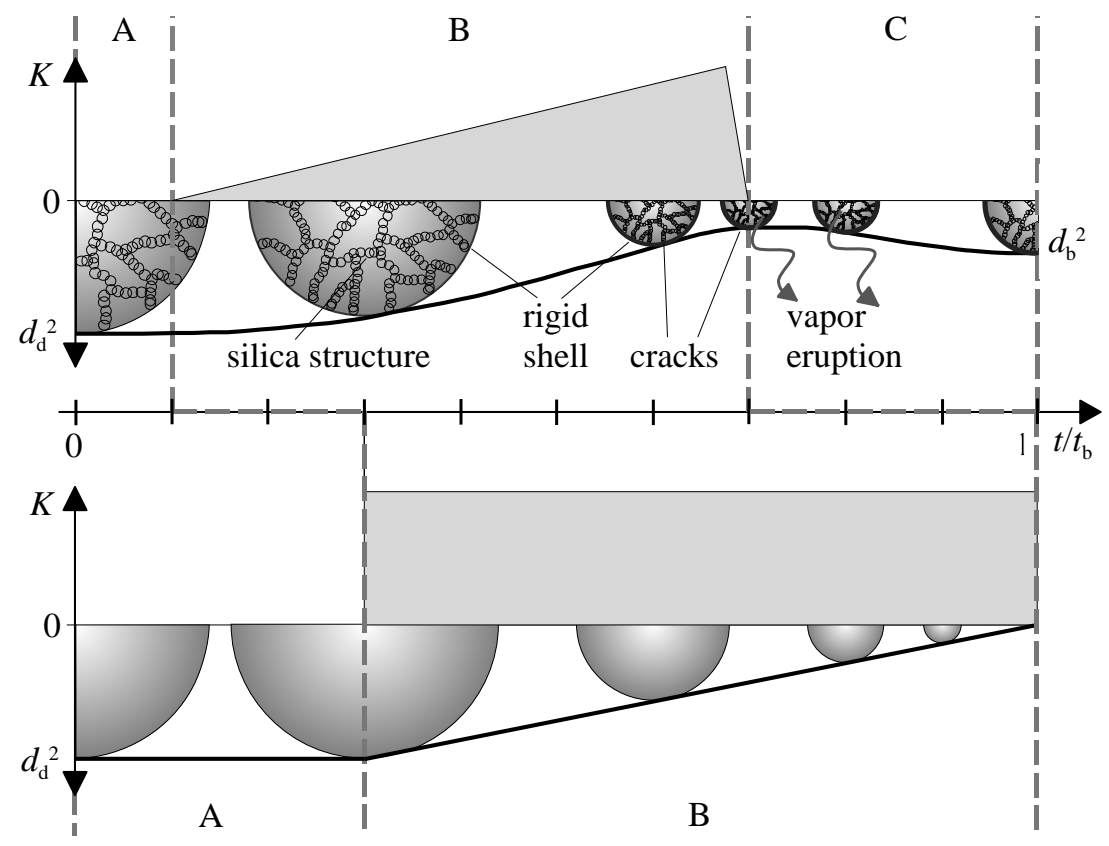

Pure JP-8

Figure 9. Droplet burning process 


\section{Crack formation and vapor eruption}

Due to the formation of a rigid silica structure escaping combustion products and entrapped JP-8 vapor can cause localized rupture of the silica lattice. This behavior was observed at silica concentrations higher than $3 \%$ and was much more pronounced at higher concentrations. Figure 10 shows the occurence of two cracks in a JP-8 droplet with $4 \%$ silica at approximately $75 \%$ of the total burning time. A long straight crack on the left side of the image and a circular-shaped crack on the right side of the droplet can be distinguished clearly.

Figure 11 depicts a series of selected high speed frames showing the eruption of a vapor stream. At a time $t=t^{*}$ a spontaneous JP-8 fuel vapor eruption can be seen on the right side of the droplet (frames 1 and 2). About $8 \mathrm{~ms}$ later ignition of the ejected JP- 8 vapor takes place (frame 3 ) with a following burning of the vapor-

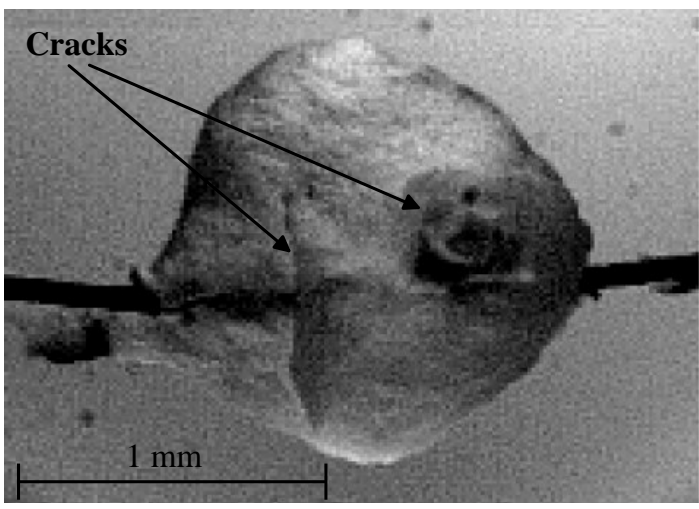

Figure 10. Crack formation in the silica structure ized fuel (frames 4 and 5). Approximately $24 \mathrm{~ms}$ after the eruption all the ejected fuel has been burned (frame 6). Further fuel vapor eruptions can be seen almost till the end of the burning process.
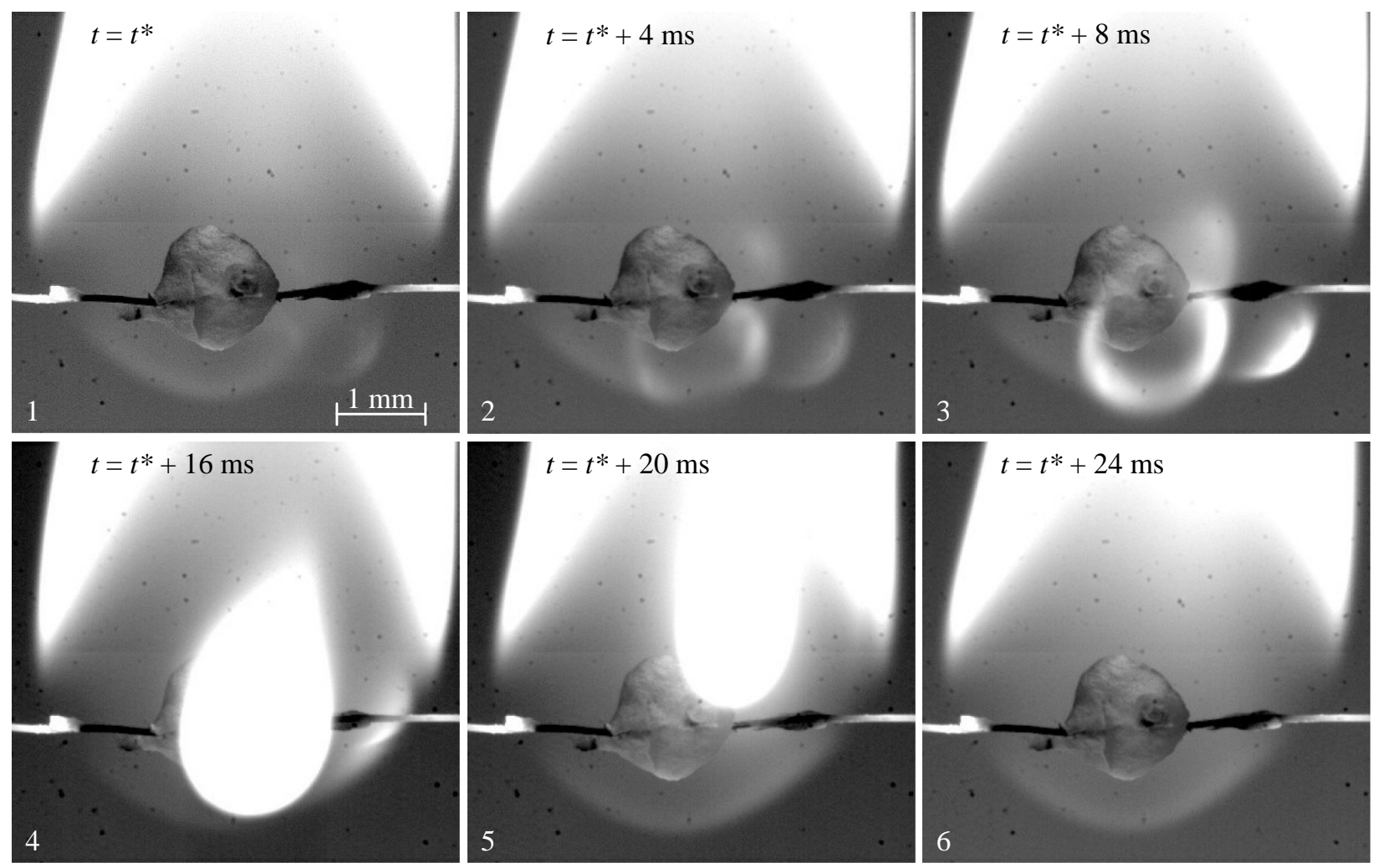

Figure 11. Fuel vapor eruption

The formation of fuel bubbles inside a droplet during the burning process have been reported from several authors when using slurry fuels or organic-based gelled fuels. With metallized slurries a shell disruption and a shattering or explosion of the droplet due to an increased inner pressure can be seen. ${ }^{2,24}$ Because of the expandable viscous shell of organic-based gelled fuel droplets an expansion of the droplet due to a swelling of the vapor bubble occurs. When the bubble ruptures, the fuel vapor is released, and the droplet shrinks to the surface of the remaining liquid. ${ }^{15,22}$ This process induces a periodical swelling and diminishing of the droplet volume during the burning process, whereas with the inorganic gelling agent a constant decrease of the droplet and at the end a slight increase takes place (see figure $7(\mathrm{~b})$ ). 


\section{Droplet temperature during combustion}

The droplet burning temperature is depicted for pure JP-8 in figure 12 (a) and for gelled JP-8 with $4 \%$ silica in figure 12 (b). The overall burning process can be divided into an initial transient which includes the point of ignition, followed by a relatively constant droplet burning which depends of the amount of gelling agent, and a final heating up at the end of burning when the flame is in direct contact with the thermocouple with maximum temperature at the point of flame extinction (see also figure 9).

After the initial transient, which is a function of the gelling agent amount $M$ and the droplet size, the droplet burns at a temperature of $T_{\mathrm{d}}=350 \ldots 450 \mathrm{~K}$. This temperature lies within the range of the boiling temperature of the JP-8 (see table 2), which shows also that the assumption used in equation (7), that temperature is the boiling temperature of the JP-8, is acceptable within the present study.

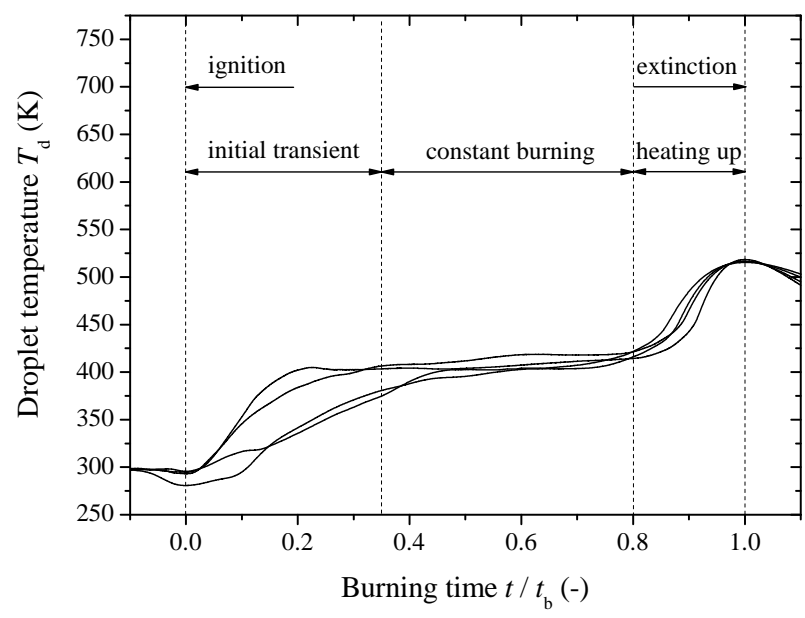

(a) Pure JP-8

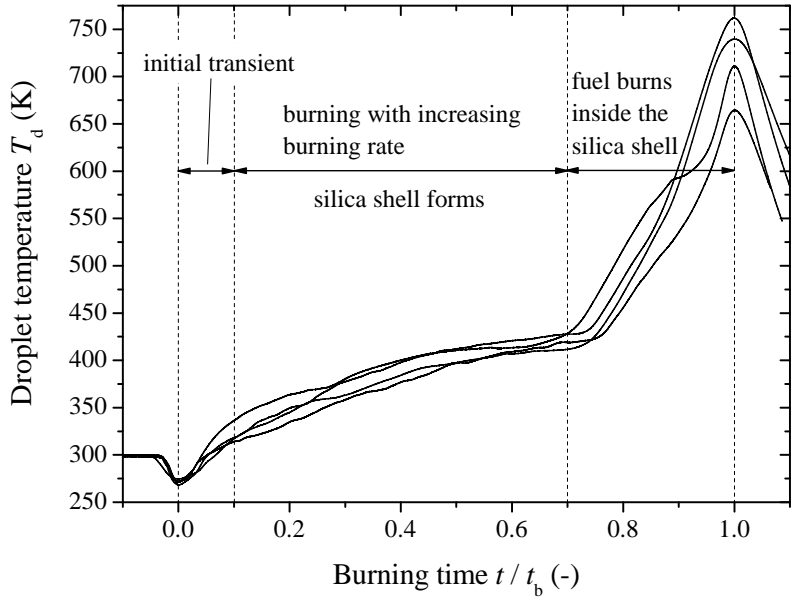

(b) JP-8 with $4 \%$ silica

Figure 12. Droplet temperature

The burning process after the initial transient is controlled by the amount of silica. For pure JP-8 (see figure $12(\mathrm{a})$ ) a constant burning temperature has been measured. The constant burning temperature indicates the agreement with the typical $d^{2}$-law behavior for this period, as a comparison with figure 7 (a) shows. On the other hand, the constant increase of burning temperature for the gelled JP-8 corresponds with a gradual increase of $K^{\prime}$. When the silica shell contraction is complete and residual fuel inside begins to burn, the measured temperature inside the droplet rises very quickly. For the ungelled pure JP-8 droplets, the temperature rise at the end of the burning time is caused when the flames touch the thermocouple tip. For the gelled propellant, the temperature rises when the fuel on the outside of the rigid silica shell is burned. A heating up of the rigid structure has been detected due to the burning process of the inside entrapped liquid. For gelled JP-8 droplets, the steep temperature rise depicted in figure 12 (b) is connected with the time of the minimum droplet size at about $70 \ldots 80 \%$ of the droplet burning time (see figure $7(\mathrm{~b})$ ). Due to the agglomeration of the silica shell however, the flame never touches the thermocouple tip directly.

\section{Conclusion}

Within the present study, rheological behavior and single droplet burning experiments using hydrocarbon fuel JP-8 and untreated fumed silica $\left(\mathrm{SiO}_{2}\right)$ as an inorganic gelling agent are described. For both, the pure ungelled liquid as well as for the silica gels the typical $d^{2}$-law behavior can be used to describe the droplet burning. However, deviations from the ideal $d^{2}$-law behavior increase with increasing silica content. A simple empirical correlation can be expressed to predict the burning behavior of gelled droplets by the application of a time-averaged effective burning rate constant. The commonly used assumption of an infinite heat conduction cannot be used for inorganic gelled droplets. The optical analysis of single droplet burning experiments has shown the build-up of a rigid silica structure which stays unburned. Inside entrapped propellant vaporizes and erupts with ignition at irregular intervals in the second half of the droplet burning life time, especially for highly gelled droplets. The droplet burning temperature lies within the range of the boiling temperature 
of the JP-8. However only for ungelled droplets a uniform temperature distribution inside the droplet and connected with that a constant burning rate behavior can be detected.

Ongoing investigations at Purdue University consider rheological behavior and single droplet combustion of gelled hypergolic rocket engine fuels like $\mathrm{MMH}$, using organic cellulose-based gelling agents.

\section{Acknowledgement}

The research presented in this paper was made possible with the financial support of the U.S. Army Research Office under the Multi-University Research Initiative (MURI) grant number W911NF-08-1-0171.

The help of Travis Kubal with the temperature measurements and the excellent support of Paulo H. S. Santos with the rheological characterization of the gelled propellants is greatly acknowledged by the authors.

\section{References}

\footnotetext{
${ }^{1}$ Teipel, U. and Förter-Barth, U., "Rheological Behavior of Nitromethane Gelled with Nanoparticles," Journal of Propulsion and Power, Vol. 21, No. 1, January-February 2005, pp. 40-43.

${ }^{2}$ Natan, B. and Rahimi, S., "The Status of Gel Propellants in Year 2000," Combustion of Energetic Materials, Kuo, K. K. and deLuca, L., 2001.

${ }^{3}$ Pein, R., "Gel Propellants and Gel Propulsion," 5th International High Energy Materials Conference and Exhibit DRDL, Hyderabad, India, November 23rd-25th 2005.

${ }^{4}$ Rahimi, S., Hasan, D., and Peretz, A., "Development of Laboratory-Scale Gel-Propulsion Technology," Journal of Propulsion and Power, Vol. 20, No. 1, January-February 2004, pp. 93-100.

${ }^{5}$ Rapp, D. C. and Zurawski, R. L., "Characterization of Aluminium/RP-1 Gel Propellant Properties," 24th AIAA/ASME/ SAE/ASEE Joint Propulsion Conference, Boston, MA, July 11th-13th 1988, AIAA-88-2821.

${ }^{6}$ Hodge, K., Crofoot, T., and Nelson, S., "Gelled Propellants for Tactical Missile Applications," 35th AIAA/ASME/ SAE/ASEE Joint Propulsion Conference 83 Exhibit, Los Angeles, CA, June 20th-23rd 1999, AIAA 99-2976.

${ }^{7}$ Cabot Corporation, "CAB-O-SIL@Untreated Fumed Silica-Properties and Functions, Mechanisms of CAB-O-SIL®," Technical Bulletin CGEN-8A, 2009.

${ }^{8}$ Braun, D. B. and Rosen, M. R., Rheology Modifiers Handbook: Practical Use and Application, William Andrew Publishing, 2000

${ }^{9}$ Edwards, T., Harrison, W. E., and Maurice, L. Q., "Properties and Usage of Air Force Fuel: JP-8," 39th AIAA Aerospace Sciences Meeting \& Exhibit, Reno, NV, January 8th-11th 2001.

${ }^{10}$ U.S. Army Tank-automotive and Armaments Command, Detail Specification Fuel, Diesel, Referee Grade, Warren, MI, November 2nd 2002, MIL-DTL-46162E.

${ }^{11} \mathrm{HQ}$ AFPET/AFTT, Turbine Fuel, Aviation, Kerosene Type, JP-8 (NATO F-34), NATO F-35, and JP-8+100 (NATO F-37), Wright-Patterson AFB, April 11th 2008, MIL-DTL-83133F.

${ }^{12}$ Coguill, S. L., "Synthesis of Highly Loaded Gelled Propellants," Tech. rep., Resodyn Corporation, Butte, MT, 2009.

${ }^{13}$ Ferguson, J. and Kemblowski, Z., Applied Fluid Rheology, Elsevier Science Publishing Co., Inc., New York, NY, 1991.

${ }^{14}$ Madlener, K. and Ciezki, H., "Analytical Description of the Flow Behavior of Extended Herschel-Bulkley Fluids with Regard to Gel Propellants," 36th International Annual Conference of ICT \& 32nd International Pyrotechnics Seminar, Karlsruhe, Germany, June 28th-July 1st 2005.

${ }^{15}$ Ciezki, H. K. and Natan, B., "An Overview of Investigations on Gel Fuels for Ramjet Applications," ISABE2005, 17th Int. Symposium on Airbreathing Engines, Munich, Germany, September 4th-9th 2005.

${ }^{16}$ Arnold, R., Santos, P. H. S., Kubal, T., Campanella, O., and Anderson, W. A., "Investigation of Gelled JP-8 and RP-1 Fuels," International Conference on Chemical Engineering (ICCE'09) within The World Congress on Engineering and Computer Science 2009 (WCECS 2009), San Francisco, CA, October 20th-22nd 2009, Published in Proceedings of the World Congress on Engineering and Computer Science 2009, Vol I, ISBN 978-988-17012-6-8, pp. 63-68.

${ }^{17}$ Rahimi, S. and Natan, B., "Atomization Characteristics of Gel Fuels," 34th AIAA/ASME/SAE/ASEE Joint Propulsion Conference \& Exhibit, Cleveland, OH, July 13th-15th 1998, AIAA 98-3830.

${ }^{18}$ Bar-or, D. and Natan, B., "Experimental Evaluation of Gel Fuel Droplet Burning Rates at Sub and Supercritical Conditions," 44th AIAA/ASME/SAE/ASEE Joint Propulsion Conference /ES Exhibit, Hartford, CT, July 21st-23rd 2008, AIAA 2008-4874.

${ }^{19}$ Nahamoni, G. and Natan, B., "Investigation of the Combustion Process of Gel Propellants," 33rd AIAA/ASME/ SAE/ASEE Joint Propulsion Conference and Exhibit, Seattle, WA, July 6th-9th 1997, AIAA-1997-2973.

${ }^{20}$ Nachmoni, G. and Natan, B., "Combustion Characteristics of Gel Fuels," Combustion Science and Technology, Vol. 156, 2000, pp. 139-157.

${ }^{21}$ Solomon, Y. and Natan, B., "Experimental Investigation of the Combustion of Organic-Gellant-Based Gel Fuel Droplets," Combustion Science and Technology, Vol. 178, 2006, pp. 1185-1199.

${ }^{22}$ Solomon, Y., Natan, B., and Cohen, Y., "Combustion of Gel Fuels Based on Organic Gellants," Combustion and Flame, Vol. 156, 2009, pp. 261-268.

${ }^{23}$ Turns, S. R., An Introduction to Combustion-Concepts and Applications, McGraw-Hill Series, 2nd ed., 2000.

${ }^{24}$ Lee, A. and Law, C. K., "Gasification and Shell Characteristics in Slurry Droplet Burning," 25th AIAA/ASME/ SAE/ASEE Joint Propulsion Conference, Monterey, CA, July 10th-12th 1989, AIAA 89-2437.
} 